\title{
0 ensino de Filosofia e discernimento no mundo contemporâneo: questões atuais
}

The philosophy teaching and discernment in the contemporary world: current issues

\author{
Alexandre Filordi de Carvalho* \\ Universidade Federal de São Paulo
}

Resumo O objetivo do artigo é desenvolver a ideia de que é preciso investir no ensino de Filosofia como ferramenta de produção de discernimento. A hipótese é a de que o discernimento seria a capacidade elementar que se aprende para poder agir com o pensamento, com as ações e as atitudes para consigo mesmo e para com o mundo. Para tanto, o texto elege três níveis de questões atuais que desafiam o discernimento pelo aprendizado da Filosofia: a experiência dos sujeitos com a sociedade capitalística e de consumo, a homogeneização das potencialidades subjetivas e, por fim, a colonização do sentimento de impotência na transformação da própria realidade social. O pensamento de Deleuze e Guattari são convocados como fundo analítico desta proposta.

Palavras-Chave: Ensino de Filosofia, Discernimento, Sociedade capitalística, Deleuze e Guattari.

Abstract The aim of the paper is to develop the idea that we need to invest in Philosophy teaching as discernment production tool. The hypothesis is that the discernment would be the basic capacity that one learns in order to act with the thought, with the actions and attitudes to himself and to the world. For this purpose, the text elects three levels of current issues that challenging the discernment by the Philosophy teaching: the experience of the subjects with the capitalistic and consumer society, the homogenization of subjective potential and finally the colonization of sense of powerlessness to change the social reality itself. The thought of Deleuze and Guattari are called as analytical background of this proposal.

KEYWORDS: Philosophy teaching, Discernment, Society capitalistic, Deleuze and Guattari. 
O sujeito, na condição de fator de ruptura, está em eclipse.

GUATTARI, 2004, p. 237.

\section{Considerações iniciais}

Ao menos três vertentes se atualizam como elementos desafiadores ao ensino de Filosofia. Em primeiro lugar, como trataram de mostrar Carvalho, Novaes e Oliveira (2012), ainda há um acentuado déficit na qualidade da formação do professor atuante na área da Filosofia. Isto se deve pelo montante considerável de bacharéis e de licenciados em distintas áreas que buscam uma formação complementar para atuar no campo da Filosofia. Decorre que a própria qualidade de formação desses professores passa a refletir na composição do trabalho pedagógico em sala de aula. Por vezes, há a utilização do que se descobriu ser uma "filosofia do cotidiano", ou seja, a manipulação de debates livres no curso das aulas, deflagrados conforme o interesse dos alunos e, quase sempre, mediado por um senso comum eivado por aquilo que Lebrun (2009) denominava de bagagem de bazar.

Em segundo lugar, o ensino de Filosofia é desafiado pelas ferramentas utilizadas para dar consecução à sua própria tarefa. Uma vez obrigatório no ensino médio, o ensino de Filosofia vê-se face à face com as próprias estratégias de Estado, com o intuito de aparamentar os seus professores com recursos didáticos. Exemplo maior dessa dimensão encontra-se no Programa Nacional de Livros Didáticos - PNLD 2015 para a área. Com a recomendação de cinco obras, ${ }^{1}$ o PNLD visa à uma "construção da identidade do ensino de Filosofia no Brasil” (BRASIL, 2015, p. 9). Essa identidade, contudo, está consignada a uma série de ajustes de demandas produzidas pelas políticas públicas educacionais. Com efeito, as indicações de suportes didáticos acabam por acarretar em um zoneamento do ensino de Filosofia, potencializando um campo que se estabiliza mais ou menos ao redor de um leque possível de escolhas, sobretudo quando se trata do ensino da Filosofia na escola pública. Certamente que, assim, seria um pouco ingênuo pensar que o "livro didático", tão somente, "torna-se roteiro de trabalho e interlocutor do professor na sua concepção e em suas práticas de ensino de Filosofia” (BRASIL, 2015, p. 9), mas há que se indagar se o livro didático não acaba se tornando, também, um atavio no exercício livre do ensino de Filosofia, ou um tipo de guia amuleto, ou ainda um redutor de outras vertentes de abordagem e de trabalho didático-filosófico. Desde nomes já consagrados e conhecidos no cenário do ensino de Filosofia no Brasil até o surgimento de rostos novos, como é o caso de Silvio Gallo, a questão da escolha entre o componente didático e o seu uso está investido para além de juízos de valores, de consequências para o próprio tratamento com a experiência do ensinar. $\mathrm{O}$ ensino de Filosofia, nesse caso, já denota uma opção política e, portanto, uma espécie de filtragem com relação àquilo que se processa entre o ensinar e o aprender Filosofia.

A terceira vertente a se atualizar nos desafios do ensino de Filosofia é menos objetiva, mas não por isso de importância menor. Trata-se da recepção da Filosofia como disciplina formadora no conjunto curricular do ensino médio. De modo mais preciso, o ensino de Filosofia reatualiza o seu velho: para quê? Se, de um lado, há o problema evidente da formação do professor de Filosofia e, de outro lado, os elementos 
didáticos com os quais o professor faz valer o exercício do ensino, logo, as suas escolhas de conteúdo e a opção do tratamento do que ensinar, pode-se dizer que ambas questões têm de acertar as contas com as finalidades pelas quais se faz do ensino de Filosofia algo a se ensinar. Consequentemente, o que está em jogo é o que o ensino de Filosofia pode como empoderamento formativo dos alunos que passam pelo seu ensino. No final das contas, é a finalidade do ensino de Filosofia que emerge aqui como questão.

Lebrun (2009), no texto Por que filósofo?, ressaltava o perigo implicado no filosofar meramente institucionalizado. Para ele, essa institucionalização replicava, na modernidade, uma filosofia perennis, contaminada pelo manual filosófico. Em nosso caso, bem que pode ser o didatismo sôfrego e coxo amparado apenas no domínio de uma vertente reprodutiva de certo manual ou livro didático. Como é de se esperar da ironia peculiar de Lebrun (2009, p.19-20), ele argumentava que "os manuais podem muito bem tentar fazer com que os jovens das classes finais do curso secundário ${ }^{2}$ acreditem serem eles descendentes de Sócrates; mas neles apenas vejo sobrinhos de Victor Cousin”. A menção a Victor Cousin, cum grano salis, faz-nos pensar na experiência da Filosofia como um sistema de pensamento eclético, parcializado e conduzido por múltiplas orientações com o intuito de se sobrepor a uma espécie de cadeia lógica, pretensamente evolutiva desde a história da Filosofia. A "bagagem de bazar" filosófica se orienta nessa direção.

Levando em consideração essa conjuntura, gostaria de sustentar, neste texto, a ideia de que é preciso investir no ensino de Filosofia como ferramenta de produção de discernimento. A hipótese é a de que o discernimento seria a capacidade elementar que se aprende para poder agir com o pensamento, com as ações e as atitudes com o intuito de compreender situações em suas distinções valorativas, intelectivas, volitivas; mas também seria perceber, com clareza, a distinção e a diferença de tudo que possa permear as condições histórico-sociais que engendram a materialidade existencial, também responsáveis por formar juízos, apreciações, avaliações nos sujeitos, a fim de que eles possam aprender a identificar as causas e os efeitos de se viver como se vive, de se pensar como se pensa, de se fazer o que se faz e de agir como se age.

Assim, eu pensaria que o ensino de Filosofia tem como tarefa urgente capacitar os alunos a discernir três experiências contemporâneas, na mesma proporção em que aprendem a discernirem-se nessas experiências. Essas experiências, ao mesmo tempo, são mediadoras de suas vivências histórico-sociais e também são conectores de produção de sentidos, de valoração, de reprodução de papéis sociais, de alocação de conformismo intelectual, de reprodução de ideias preconceituosas e de paralização de ações críticas e questionadoras. Trata-se da experiência dos sujeitos com a sociedade capitalística e de consumo, a homogeneização das potencialidades subjetivas e, por fim, a colonização do sentimento de impotência na transformação da própria realidade social.

Mesmo que a qualidade da formação do professor de Filosofia seja convocada para tanto, bem como a sua competência didático-pedagógica para instrumentalizar o seu aluno na direção aqui proposta - o que de todo modo o faz valer de um livro 
didático ou de um recorte da História da Filosofia - o ponto a que intento chegar é o de pensar na possibilidade de fazer do ensino de Filosofia um meio de discernir ${ }^{3} \mathrm{e}$ de discernir-se e, por suposto, de agir no e com esse mundo delineado historicamente.

\title{
Discernir e discernir-se na sociedade capitalística e de consumo
}

Na concepção de Guattari (1987; 2011), a sociedade capitalística é caracterizada pelo transbordamento das relações concretas, baseada não apenas no modo de produção restrito à sua materialidade. Mas trata-se de pensar nos fluxos que são também produzidos pela multiplicidade de significantes que têm a potencialidade de modelar os comportamentos, os desejos, as ações dos sujeitos a serviço de formações sociais determinadas. Segundo Guattari, existem alguns indícios indeléveis de como os sujeitos históricos são produzidos a partir de uma série de máquinas de produção de experiências subjetivas. Para ele, tais máquinas encontram-se no grande contexto dos fluxos da sociedade capitalística e de consumo.

A subjetividade é produzida por agenciamentos de infantilização, e esse é o primeiro indício. Ao vivermos em um possível pré-estruturado, somos atravessados por todo tipo de instalação maquínica eivada por instituições estatais, equipamentos coletivos, conjuntos de saberes, matrizes de comportamento, referentes semióticos: artes visuais e mídias, sons, imagens, moda, textos de toda a sorte; mas também por redes poderosas de representação e de significação dominantes, responsáveis por tutelar a potencialidade subjetiva de cada um. São verdadeiras filtragens, de controle e de mediação dos afetos e das percepções. Nessas filtragens aprendemos a como enxergar, ouvir, sentir, provar, interagir, mostrar-se, falar, imaginar, mas também o que, quando, para quê, para quem. A economia subjetiva capitalística tem por função transformar o sujeito em sujeito indeterminado, é o que parece a Guattari:

\begin{abstract}
pensam por nós, organizam por nós a produção e a vida social. Além disso, consideram que tudo o que tem a ver com coisas extraordinárias - como o fato de falar e viver, o fato de ter que envelhecer, de ter que morrer - não deve perturbar nossa harmonia no local de trabalho e nos postos de controle social que ocupamos, a começar pelo controle social que exercemos sobre nós mesmos. (GUATTARI, 2005, p. 50).
\end{abstract}

Ora, a capacidade de escolha própria tornou-se uma fechadura enferrujada para o sujeito contemporâneo. O tempo todo ele é teleguiado e condicionado pelos signos massificadores. Informações ilegítimas e falsificadas multiplicam-se infinitamente nas redes sociais. Quase nunca elas são averiguadas, quase sempre são propaladas com fortes convicções assentadas na imediata percepção de questões e de problemas que, em um mundo adulto qualquer, exigiria um mínimo de esforço e de empenho para as suas compreensões, discernimentos e julgamentos.

O segundo indício de como a subjetividade é maquinada na sociedade capitalística encontra-se nas produções de agenciamentos de culpabilização. A culpa é forjada ao passo que a comparação se incrustou em nossa subjetividade pela me- 
dida de valor comparativo instituído por significantes de consumo inquebrantáveis. O que consumimos, inevitavelmente, indica a nossa finitude material. Soterrados na impotência de se ter tudo, logo descobrimos o quão insignificante e insuficiente são as nossas energias para suprir a frustração constante que nos subordina à defasagem que não se repõe. "O que você vale na escala de valores reconhecidos enquanto tais na sociedade? "Que etiqueta poderia classificar você?" (GUATTARI, 2005, p. 49). Tais indagações, segundo os termos literais de Guattari, fazem com que comecemos a indagar: "afinal de contas quem sou eu? Será que sou uma merda (sic)?" (1995, p. 49).

A culpabilização é fundamental para estabilizar o campo social capitalístico. Os seus quadros de referências nos lançam em um buraco negro que draga e bloqueia os processos de afirmação singular do campo subjetivo. Nesse campo esburacado, o desejo está sempre minado e sabotado para bloquear as condições efetivas de processos de singularidade. Passamos a viver decalcados sobre a imagem de um fantasma que nunca poderemos ser, claro está, para renovar as forças que pretensamente hão de superar toda a nossa frustração: sempre é preciso trabalhar mais para isso ou aquilo. Podemos pensar no tipo de trabalho que executamos com as suas possíveis derivações: onde moramos, como nos locomovemos, como nos divertimos. A culpabilização é um modo de atualizar uma produção de subjetividade assujeitada, como se o "nosso próprio direito de existência desabasse" (GUATTARI, 1995, p. 49). Somos, assim, sobrecarregados de um pesado investimento afetivo que atua como coeficiente classificador ao longo do tecido social.

Infantilização e culpabilização, par e passo, são cultivadas no solo fértil dos agenciamentos que incidem nos modos de temporalização. Temporalização não é o tempo. É a sua partilha e distribuição, conforme a energia aplicada em uma determinada finalidade, numa fração precisa e controlada de tempo. Aqui, o velho lema time is money transforma-se em história de carochinha, pois o tempo não é mais uma medição produtiva de ordem meramente econômica. A regulação temporal incide sobre todos os níveis da existência, sobrecodificando os circuitos e as consistências de nossos possíveis. A temporalização capitalística regrada dita os ritmos e os planos do que pode ou não pode ser afirmado como matéria a ser vivida, como cadência consumível de reapropriação subjetiva. É para isso que serve a rotina:

todas as relações com o espaço, com o tempo e com o cosmos tendem a ser completamente mediadas pelos planos e ritmos impostos, pelo sistema de enquadramento dos meios de transporte, pela modelização do espaço urbano, do espaço doméstico, pela tríade transporte-mídia-equipamento coletivo. (GUATTARI, 1995, p. 53).

É assim que vemos Cipriano Algor, personagem em A caverna, de José Saramago (2000), dando-se conta de que as mudanças pensadas por ele, para viabilizar a economia de tempo e de material na produção de suas estatuetas, acabaria destinando-o a um modo de ser preciso: "a partir desse dia, Cipriano Algor só interrompeu o trabalho na olaria para comer e dormir". Em grande parte, essa mesma experiência ocorre conosco. A temporalização capitalística toma toda a dimensão de nossa vida. Por ela, somos conduzidos como pequenas crianças sem vontade própria. Dentro dela, a culpa acerca de nossa incapacidade de fazer e de ter tudo nos assola dia e noite. 
Não saberíamos contar a multitude de operadores intermediários que se instalam nos agenciamentos de infantilização, de culpabilização e de controle da temporalidade. Mas em cada operador passamos por uma nova iniciação que tenta moldar toda a nossa energia e o nosso potencial singular para derivar uma subjetividade normada, normalizada, serializada, consensual e presa a um círculo vicioso. Neste caso, o consumo é um operador mais do que presente em nossa sociedade. Ele é uma máquina poderosíssima e hiper-eficaz de injetar em nosso campo subjetivo toda forma de representação: faça assim, faça assado; seja assim e não de outro modo. As representações estabilizam o campo da sociedade capitalística, cuja mutação é tão insensível como em uma língua estabilizada em seus acordos e em suas regras sintáticas. O consumo tornou-se o nosso latim. Componente difusor de uma semiótica em sua vocação de universalidade. Investimento superegóico e cristalizador de atitudes e de comportamentos; divisor binário e falocrático (quem pode mais?); assujeitamento generalizado; organizador dos espaços; gerente do tempo (consumo em sua rapidez: acordar, trabalhar, estudar, dormir, acordar...); consumo: compositor de componentes semióticos corporais (função somática e perceptiva); consumo: processador do que se torna relevante ou irrelevante, enfim, um produtor de experiências concretas para os sujeitos históricos.

\section{Discernir e discernir-se na homogeneização das potencialidades subjetivas}

No horizonte desse contexto, não podemos ignorar que a junção de todo entroncamento dos fluxos produtivos da sociedade capitalística passa pelo papel que as instituições exercem na sociedade. Elas são espécie de conectores que mantém a ordem homeostática, por exemplo, da infantilização, da culpabilização e do controle da temporalidade em dia. Não é de se espantar a importância da escola nessa conjuntura. Há um complexo de formação na escola, coextensivo às maneiras pelas quais os alunos são colocados para trabalhar suas disposições mentais, suas potencialidades afetivas, suas visões e concepções de mundo, sem contar as suas auto-visões e auto-concepções. Ocorre, contudo, que quase sempre o que se mobiliza é a energia em virtude da necessidade de os alunos serem adaptados às funções produtivas e sociais que a própria sociedade capitalística espera deles.

A ordem capitalista pretende impor aos indivíduos que vivam unicamente num sistema de troca, uma traduzibilidade geral de todos os valores para além dos quais tudo é feito, de modo que o menor de seus desejos seja sentido como associal, perigoso, culpado. (GUATTARI, 1987, p. 202).

O fato de o ensino de Filosofia passar, forçosamente, pela instituição escolar faz-nos refletir sobre as suas implicações iminentes com o caráter reprodutivo da experiência com o pensamento filosófico. Quer dizer, meramente institucionalizado, o ensino de Filosofia pode apenas contribuir para um acúmulo de conhecimentos implicados em uma outra tarefa burocrática curricular, cumprindo apenas a ordem sistemática de conteúdos traduzidos na arte professoral igualmente burocrática. 
Deleuze e Guattari em O que é a flosofia? (1997, p. 137), alertavam para o fato de que "quando a filosofia se reterritorializa sobre o Estado de direito, o filósofo se torna professor de filosofia”. Em questão não está em saber se professor de filosofia é ou não filósofo. Esta discussão, no meu modo de ver, é supérflua à luz do propósito de fazer da Filosofia uma ferramenta a potencializar transformações nos sujeitos que entram em contato com ela, quer seja com respeito ao mundo em que vivem, consigo mesmo ou com os outros. O que está em jogo é o fato de que a experiência com a Filosofia sempre corre o risco de se burocratizar. Ela pode ser apenas um outro tipo de apetrecho estatal capaz de manter o conhecimento pelo conhecimento como direito adquirido de quem passa pela escola, e não como ferramenta de discernimento entre o que ocorre quando se é educado e a destinação final do educando na própria sociedade.

Deste ponto de vista, com efeito, o ensino de Filosofia não passaria de uma disciplina qualquer, engajada no direito de acesso universal à educação. Ela apenas comporia o núcleo segmentar das disciplinas pelas quais os alunos entram em contato na escola. Com efeito, o ensino de filosofia preencheria tão somente uma determinação curricular, embora, como já indicava Marx (1988, p. 270), ao explanar sobre o caráter capitalista da manufatura, mantendo a ordem dos conhecimentos responsáveis por alimentar a formação do trabalhador parcelar, coincidindo-se apenas com o que se exige, de modo assessório, para que alguém se submeta à "vontade do corpo social".

Mas ao sustentar que o ensino de Filosofia pode ser experiência com o meio de discernimento, o seu professor é convidado a atuar interrompendo a lógica desta composição. Mesmo que o ensino de Filosofia seja considerado relevante para o exercício do pensamento, o acesso à cultura geral, para a formação da cidadania e para o pensamento crítico (BRASIL, 2014), é fácil ver emergir uma margem da funcionalidade filosófica que descredita e ignora o propósito pragmático com o envolvimento de instrumentos que possam ser utilizados como "lutas relativas às liberdades, novos questionamentos da vida cotidiana, do ambiente do desejo" (GUATTARI, 1987, p. 219), e de todo tipo de contestação da homogeização subjetiva, fundamentada na sociedade capitalística. Esse diagnóstico fica patente na apresentação do PNLD - Filosofia:

No contexto essencialmente dinâmico das práticas e das apropriações de saberes, próprio às circunstâncias concretas da sala de aula e da investigação sobre a Filosofia e seu ensino, o livro didático deve ser o fiel da balança que marca o delicado equilíbrio entre esses dois universos complementares. (BRASIL, 2014, p. 10).

Que o livro didático seja apenas um meio para a finalidade do ensino é algo a ser ponderado com criticidade. Mas, por outro lado, deixar de conceber a própria instrumentalidade da apropriação de saberes também como parte do fiel da balança entre investigação e ensino de Filosofia, é furtar-nos ao empoderamento do ensino de Filosofia como valor formador para a ação do pensamento e, como veremos a seguir, da ação política de que passa pela Filosofia.

$\mathrm{Na}$ tarefa que envolve o ensino de Filosofia, não podemos abrir mão do fato de que a potência específica com o manejo do universo conceitual refina a capacidade 
dos alunos para se munirem de condições cada vez mais perspicazes e refinadas linguisticamente e, portanto, deslocadas das redes de significante-significados medíocres que modelam os indivíduos de acordo com as imagens reguladoras e as funções chaves dessa mesma sociedade, como sugeriu Guattari (2004). Isso não é uma mera aposta ao esclarecimento cognocentrista, ou ao velho sapere aude kantiano, cuja aposta na coragem de fazer uso do próprio entendimento bastaria ao projeto da Aufklärung (KANT, 2005). A aposta está no fazer, na busca pela ruptura de toda ordem do significante; está no poder optar agir fora da "mesma coisa", da "repetição como morte", da "serialidade", dos "mesmos circuitos", das "modelagens reguladoras", conforme termos de Guattari (2004).

Se o ensino de Filosofia conseguir operar seus instrumentos histórico-conceituais nesse horizonte, certamente seriam dadas às potencialidades subjetivas dos alunos novos elementos de discernimento entre a repetição dos fluxos capitalísticos e a afirmação produtiva de novas experiências fora do circuito da infantilização, da culpabilização e da administração temporal da existência. O ensino de Filosofia tem a oportunidade, assim, de sair do ciclo das disciplinas de valores de conformação, dando lugar aos valores de formação para o discernimento.

\section{Discernir e discernir-se na impotência da ação transformadora de si e da realidade social}

Aprender a discernir é aprender a pensar, e pensar é engajar-se na realidade, o que demanda ação. Logo, discernir é pensar e agir. Deleuze e Guattari (1997) sugeriram que a certa altura, conforme o avanço dos condicionantes da sociedade capitalísticas, a tarefa da Filosofia de afirmar a sua criatividade questionadora pela criação de conceitos entrou em padecimento pela própria promoção comercial da Filosofia. Constrangeria a eficácia da Filosofia, nesse sentido, se ela continuasse a se afinar com "os benefícios sociais do ponto de vista do capitalismo universal." (DELEUZE; GUATTARI, 1997, p. 21).

Ora, tomar a ideia de criação de conceito sem levar em consideração que, para esses autores, o que move toda a possibilidade de microrrevolução ou de revolução molecular é justamente o questionamento, o discernimento e a interrupção concreta das estruturas do poder capitalista, é enveredar-se por uma fantasmagoria sem sentido. Mais do que isso, é esvaziar a capacidade de discernimento de que a Filosofia é capaz de produzir diante das organizações e modelizações homogêneas do pensar e do agir. É preciso, de todo modo, como lembrava o próprio Deleuze à Parnet (1996, p. 40), "sacudir o modelo de aparelho de Estado, o ídolo ou a imagem que pesa sobre o pensamento, o monstro colado em suas costas".

Destarte, o ensino de Filosofia não pode ser indiferente ao chamamento para sacudir os modelos reinantes na sociedade capitalística. E um dos modelos que imperam na atualidade, como bem identificaram Boltanski e Chiapello (2009), é o da paralisia ou o da inação diante da própria realidade social. No diagnóstico desses autores, poderíamos dizer, vivemos colados nas costas de um novo ídolo, a bem da verdade, mais próximo ao horrendo ciclope com que Ulisses haveria de bancar a sua 
astúcia. Ocorre, contudo, que unicamente a astúcia da razão não sabe mais lidar com o enfraquecimento das defesas do mundo do trabalho, envolvendo a emersão de novos papeis para os sujeitos sociais em torno da flexibilização, da eficiência exploratória, da depreciação da remuneração do trabalhador - dado o inchaço do exército de reserva -, das assimetrias de informação, da banalização do sofrimento humano como espetáculo, enfim, de todo um cenário volátil para os valores que, até antes de ontem norteavam o conjunto das relações humanas.

E, para piorar o cenário, Joshua $(1999$, p. 41) faz questão de ressaltar que a escola vive no impasse de sua massificação contrastada com o direcionamento da utilidade do próprio processo de formação escolar, uma vez que "a sociedade de mercado contemporânea não mais tem necessidade de pessoas formadas no nível em que atualmente elas são formadas". Desnecessário dizer o quanto que esse fatalismo dominante se faz presente no contexto escolar.

Mas o fato de a escola passar por um processo aviltante de precarização das condições de trabalho pedagógico e da qualidade de suas estruturas gerais, apenas testemunha a consonância entre a ordem do modelo de aparelho de Estado, como mencionou acima Deleuze, e a paralisia da força de renovação da utopia social.

Suspeito que o ensino de Filosofia pode trazer uma contribuição inegável na mutação desse cenário no instante em que comece a ensinar aos alunos a dizer não à toda essa conjuntura, contestando-a pela força do meio de discernir, nas seguintes proporções. Em primeiro lugar, o ensino de Filosofia tem a oportunidade ímpar de interferir no modo como a educação tende a se institucionalizar apenas para o cumprimento do ritual do formador alienante. A Filosofia, certamente, de todos os outros demais campos disciplinares, é o mais transversal em seus temas, em suas possibilidades didáticas e no manejo de seus conteúdos. Se, de fato, "toda instituição impõe ao nosso corpo mesmo em suas estruturas involuntárias, uma série de modelos, e concebe à nossa inteligência um saber, uma possibilidade de previsão como projeto" (DELEUZE, 2004, p. 27), o ensino de Filosofia tem de ter o cuidado para não se capturar no formalismo didático-burocrático e tampouco na aderência propositiva de um conteúdo qualquer. Talvez a eficiência do discernimento a ser aprendido no ensino de Filosofia comece no instante em que o ensinar não reduplique modelagens tipificadas em torno do utilitarismo, dos valores de uso e de troca, reinantes na sociedade, e das conexões que continuar a promover a infantilização, a culpabilização e o gerenciamento da temporalização eficiente. Afetar a própria forma do ensino de Filosofia já seria, talvez, uma maneira de indicar que alguma transformação é possível de ser feita, socialmente, desde a escola. A escola não precisa repetir a escola aparelhada estatal e burocraticamente, no sentido próprio da sociedade capitalística.

Em segundo lugar, o ensino de Filosofia é desafiado a mostrar aos alunos que as coisas não precisam continuar como são, ao menos no nível do discernimento. Ora, se há algo de que o pensamento é capaz de fazer é justamente criar aferentes novos. Ocorre que a consistência subjetiva capitalista congela o próprio fluxo do pensamento criativo. Mas mostrar, como dizia Guattari (1987, p. 220), "os emaranhados de tramoias intransponíveis" é instigar mutações na subjetividade consciente dos alunos 
e, por consequência, tensionar os lugares que eles ocupam em seus grupos sociais. Se não for assim, a impotência dos sujeitos em formação, face às suas realidades sociais e face à si mesmos, permanecerá ad infinitum, repetida no torpor de que nada se pode ser feito. Assim, "os projetos de transformação social serão condenados à impotência enquanto não se inserirem em uma estratégia subversiva” (GUATTARI, 1987, p. 218), ou seja, estratégias desmanteladoras de toda axiomatização dos processos de produção de sentimento de impotência de transformação social.

Por decorrência, em terceiro lugar, o ensino de Filosofia tem a oportunidade de agenciar seus componentes teóricos ao redor de um "despertar da ação política entendida como formulação e aplicação de um propósito coletivo em termos de modo de vida" (BOLTANSKI; CHIAPELLO, 2009, p. 30). A princípio, isso pode parecer sociológico demais, ou uma redução do escopo geral da Filosofia em filosofia política. Mas não é a questão. Trata-se de ensinar que o campo da experiência histórico-social de cada sujeito é eivado de relações sociais, e que ser já denota uma experiência política da existência, ou melhor, que a condição humana já é politizada, de todo modo. Toda experiência social, já nos alertara o velho Marx em seus Grundrisse (2011), diz respeito a um sujeito igualmente social. Sujeito correlacionado à toda extensão social de sua composição, envolvendo, certamente, o registro de seu saber, "mas também seus sistemas de interação com a sociedade [...] no meio dos comportamentos sociais em todos os níveis de sensibilidade, de interiorização dos sistemas hierárquicos, de adaptação aos tecidos urbanísticos, etc." (GUATTARI, 1987, p. 213).

A considerar a apatia social com a qual convivemos, o ensino de Filosofia, sob tais argumentos, e envolvido com a produção do discernimento pode não apenas compelir o pensamento a se mover contra a paralisia e o conformismo da realidade social e da circunscrição de seus sujeitos aí, mas bem pode calibrar de outra forma os meios pelos quais o ensino de Filosofia pode potencializar tal empreitada.

\section{Ponderações finais}

O que tentei fazer neste texto foi apresentar a ideia de como é importante considerar o ensino de filosofia como uma produção de discernimento. Há um cerco que se fecha, histórica e socialmente, sobre nós que é o da consistência de produção subjetiva na sociedade capitalística, o da homogeneização das potencialidades dos sujeitos e, de modo correlacionado a estes, o cerco da paralisia ou da impotência de transformação social e dos próprios sujeitos.

O ensino de filosofia insere-se no contexto da "lógica conexionista" de nossa experiência histórico-social, conforme os termos de Boltanski e Chiapello (2009). Não saímos desta lógica como Kant gostaria que saíssemos da menoridade. As nossas Ausgänge são portas que se abrem para corredores infinitos, praticamente sem saídas, como no inferno sartriano de Entre quatro paredes. Niilismo pessimista? Claro que não, mas constatação de que o ensino de filosofia é tarefa de inacabada reposição face ao discernimento que nunca se completa enquanto instrumento a ser produzido. 
Assim, o ensino de filosofia como meio dos sujeitos aprenderem a discernir no/o mundo contemporâneo colocaria em questão a própria tarefa do professor de Filosofia em seu ensino. Mas também indagaria pelas formas e os conteúdos manejados para tanto. De todo modo, e é isso o que tentei enfatizar ao longo do texto, a relevância do ensino de Filosofia está no fato de que a Filosofia pode ser um instrumento capaz de potencializar nos alunos o discernir-se como sujeitos singulares e em suas relações sociais, a despeito das tramas da sociedade que persistem em infantilizá-los, em culpabilizá-los e em modelar as suas experiências de vida pelo controle da temporalização.

Com isso, não estou a defender o ensino de filosofia como ascese ou clínica, mas tampouco como um esoterismo a criar conceitos pelos conceitos. Penso que a questão é de fazer que o acesso ao campo filosófico, dentro das escolas, seja sinceramente um laboratório que arme os alunos para minimamente viverem com sanidade em um mundo cada vez mais adoecido pela miséria social, a exclusão, a indiferença, a falta de solidariedade, a concorrência que mutila o respeito próprio e ao próximo, a banalização da violência, o fetiche do consumismo, a aparência estigmatizante, enfim, a certeza de que pouco se pode para mudar as coisas como estão. Nesse caso, talvez valeria uma paráfrase a partir de Marx: o ensino de filosofia luta, constantemente, a favor da insubordinação do discernimento. ${ }^{4}$

\section{Referências}

BOLTANSKI, L.; CHIAPELLO, E. O novo espírito do capitalismo. São Paulo: WMF Martins Fontes, 2009.

BRASIL. Guia de livros didáticos: PNLD 2015 - filosofia: ensino médio. Brasília: Ministério da Educação, Secretaria de Educação Básica, 2014.

CARVALHO, A F. de; NOVAES, L. C.; OLIVEIRA, M. O. Por uma política de formação de professores de filosofia: da desqualificação da docência à formação aligeirada. Revista e-Curriculum (PUCSP), v. 8, p. 1-22, 2012.

DELEUZE, G. L'île déserte. Textes et entretiens 1953-1974. Paris: Les Éditions de Minuit, 2004.

DELEUZE, G.; PARNET, C. Dialogues. Paris: Flammarion, 1996.

DELEUZE, G.; GUATTARI, F. O que é a filosofia? São Paulo: Editora 34, 1997.

GUATTARI, F. Revolução Molecular: pulsações políticas do desejo. Tradução de Suely Rolnik. 3. ed. São Paulo: Brasiliense, 1987.

GUATTARI, F. Psicanálise e transversalidade. Aparecida: Ideias e Letras, 2004.

GUATTARI, F; ROLNIK, S. Micropolíticas: cartografias do desejo. 7. ed. Petrópolis: Vozes, 2005.

JOHSUA, S. Lécole entre crise et refondation. Paris: La dispute, 1999.

LEBRUN, G. A filosofia e sua história. São Paulo: Cosacnaify, 2006.

MARX, K. O capital. v. 1. 3. ed. São Paulo: Nova Cultural, 1988.

MARX, K. Grundrisse. São Paulo: Boitempo, 2011. 


\section{Notas}

${ }^{1}$ As obras indicadas são: Filosofando - introdução à Filosofia, de Maria Lúcia de Arruda Aranha e Maria Helena Pires Martins; Filosofia: experiência do Pensamento, de Silvio Gallo; Filosofia: por uma inteligência da complexidade, de Celito Meier; Fundamentos de Filosofia, de Gilberto Cotrim e Mirna Fernandes; Iniciação à Filosofia, de Marilena Chauí.

${ }^{2}$ Mantive a nomenclatura utilizada por Lebrun. Mas é claro que ele se refere ao que hoje seria o ensino médio.

${ }^{3}$ Devo a expressão a Lebrun, que dizia: A filosofia "deu-nos o meio de discernir uma gesetzmässigkeit, na qual ingênuos só veem fatos diversos, acontecimentos amontoados” (2009, p. 24)

${ }^{4}$ A frase de Marx é a seguinte: "o capital luta constantemente com a insubordinação dos trabalhadores" (1998, p. 275).

* Professor Doutor da Universidade Federal de São Paulo, Guarulhos, São Paulo.

\section{Correspondência}

Alexandre Filordi de Carvalho - Universidade Federal de São Paulo, Campus de Guarulhos. Av. Monteiro Lobato, 679. Bairro Macedo, CEP: 07252-312 - Guarulhos, São Paulo - Brasil.

E-mail: afilordi@gmail.com

Recebido em 17 de outubro de 2014

Aprovado em 14 de dezembro do 2014 